\title{
Analisis Komparasi Brand Equity Produk Smartphone Merek Oppo Dan Xiaomi
}

(Studi Pada Konsumen di Plaza Marina Surabaya)

\author{
${ }^{1}$ Imam Baihaqqi, ${ }^{2}$ Siti Ning Farida \\ 1,2UPN "Veteran" Jawa Timur
}

\author{
Alamat Surat \\ Email: imambhq30@gmail.com, sitisaham@yahoo.co.id
}

Article History:

Diajukan: 30-03-2021; Direvisi: 14-04-2021; Diterima: 28-04-2021

\begin{abstract}
ABSTRAK
Oppo dan Xiaomi merupakan brand smartphone yang banyak dikenali oleh masyarakat Indonesia. Data dari top brand menunjukkan persaingan yang cukup ketat, karena Oppo menduduki peringkat kedua sedangkan Xiaomi pada peringkat ketiga. Berdasarkan hal tersebut, peneliti ingin melakukan analisis komparasi brand equity terhadap kedua merek tersebut. Penelitian ini bertujuan untuk mengetahui perbedaan Brand Equity (Brand Awareness, Perceived Quality, Brand Association, dan Brand Loyality) pada kedua merek tersebut. Jenis penelitian ini menggunakan pendekatan kuantitatif dengan metode survey yang bersifat deskriptif komparatif. Populasi pada penelitian ini adalah pengguna smartphone Oppo dan Xiaomi di Plaza Marina Surabaya. Dalam penelitian ini menggunakan sampel sebanyak 100 responden yang terdiri dari 50 responden pengguna Oppo dan 50 responden pengguna Xiaomi. Teknik penarikan sampel dengan metode purposive sampling dengan kriteria berdomisili Surabaya, melakukan pembelian smartphone di Plaza Marina, berusia minimal 18 tahun dan memiliki smartphone merek Oppo dan Xiaomi. Berdasarkan hasil uji komparasi yang dilakukan melalui uji $\mathrm{F}$ dan uji t, maka dapat diketahui bahwa Brand Awareness dan Brand Association menunjukkan hasil yang tidak signifikan sedangkan Perceive Quality dan Brand Loyality menunjukkan hasil yang signifikan terhadap Brand Equity pada masing-masing merek.
\end{abstract}

Kata kunci: Analisis komparasi; pemasaran; brand equity

ABSTRACT

Oppo and Xiaomi are among the most recognized smartphone brands in Indonesia. Data from top brands shows that competition is quite tight, because Oppo is in second place while Xiaomi is in third place. Based on this, the researcher wants to do a comparative analysis of brand equity on the two brands. This study aims to determine the differences in Brand Equity (Brand Awareness, Perceived Quality, Brand Association, and Brand Loyality) in the two brands. This type of research uses a quantitative approach with a descriptive comparative survey method. The population in this study were Oppo and Xiaomi smartphone users at Plaza Marina Surabaya. In this study, using a sample of 100 respondents consisting of 50 respondents of Oppo users and 50 respondents of Xiaomi users. The sampling technique was purposive sampling method with the criteria of being domiciled in Surabaya, purchasing a smartphone at Plaza Marina, at least 18 years old and owning a smartphone from the Oppo and Xiaomi brands.

Based on the results of the comparative test conducted through the $F$ test and t test, it can be seen that the Brand Awareness and Brand Association showed insignificant results, while Perceive Quality and Brand Loyality showed significant results on Brand Equity in each brand.

Keywords: Comparative analysis; marketing; brand equity 


\section{PENDAHULUAN}

Perkembangan IPTEK yang mengalami kemajuan ini mengakibatkan tingkat penggunaan smartphone menjadi meningkat. Meningkatnya jumlah pengguna smartphone saat ini dikarenakan nilai fungsi smartphone sendirin sangat memudahkan masyarakat untuk melakukan aktivitas seharihari dan dapat dibawa kemana saja. Smartphone sendiri memiliki berbagai fitur untuk menunjang kebutuhan masyarakat seperti internet, email, camera, music dan game. Menurut data dari International Data Corporation menunjukkan bahwa total pengiriman smartphone meningkat hingga $49 \%$ dari kuartal sebelumnya.

Dengan meningkatnya jumlah permintaan smartphone membuat banyak produsen smartphone menciptakan produk terbaiknya diantaranya yaitu Oppo dan Xiaomi. Oppo adalah produsen elektronik yang menjual produknya lebih dari 20 negara termasuk Amerika Serikat, Asia Tenggara, Asia Selatan China, Australia, Timur Tengah, dan Afrika. Oppo sendiri berusaha meberikan produk terbaiknya dari segi kualitas dan desainnya agar masyarakat tertarik dengan produknya. Sedangkan Xiaomi adalah salah satu produsen teknologi dengan produk andalannya yaitu smartphone karena melihat perkembangan telekomunikasi yang semakin maju dan canggih menjadi peluang Xiaomi untuk mengembangkan kualitas produk smartphonenya terutama di wilayah Asia yang memiliki pangsa pasar potensial untuk smartphone.

\begin{tabular}{lll} 
BRAND & TBI 2020 & \\
\hline Samsung & $46.5 \%$ & TOP \\
Oppo & $17.7 \%$ & TOP \\
Xiacini & $10.7 \%$ & TOP \\
Vivo & $7.9 \%$ & \\
Lenava & $7.0 \%$ & \\
\hline
\end{tabular}

Gambar 1 top brand smartphone

Sumber: www.topbrand-award.com

Melihat dari persaingan kedua merek Oppo dan Xiaomi yang bersumber pada top brand dapat dilihat ketatnya persaingan dalam sektor telekomunikasi atau smartphone membuat para produsen smartphone berlomba-lomba menciptakan brand equity yang kuat. Brand equity adalah seperangkat aset dan liabilitas merek yang berkaitan dengan suatu merek, nama, simbolnya yang menambah atau mengurangi nilai yang diberikan oleh suatu barang atau jasa pada konsumen atau pelanggan. Semakin tinggi brand equity suatu produk, maka semakin tinggi pula nilai produk tersebut dimata konsumen sehingga produk yang memiliki brand yang kuat akan sulit ditiru oleh pihak lain. Dengan brand equity yang kuat, kosumen memiliki persepsi mereka terhadap produk tersebut yang tidak akan didapatkan pada produk sejenis lainnya.

\section{TINJAUAN PUSTAKA}

\subsection{Pengertian Pemasaran}

America Marketing Association (AMA) dikutip dari buku Kotler dan Keller (2016:27) yaitu pemasaran adalah merupakan suatu fungsi organisasi dan serangkaian proses untuk menciptakan, mengkomunikasikan, menghantarkan, dan memberikan nilai yang unggul kepada pelanggan, klien, mitra, dan masyarakat.

\subsection{Manajemen Pemasaran}

Kotler dan Amstrong (2014:30) mengungkapkan bahwa manajemen pemasaran sebagai seni dan ilmu memilih sasaran pasar dan membangun hubungan yang menguntungkan dengan mereka (pasar).

\subsection{Merek}

Kotler dan Amstrong (2013:230) mengatakan bahwa merek adalah sebuah nama, istilah, tanda, simbol, atau desain kesemuanya yang mengidentifikasi suatu produk atau jasa dari produsen dan perbedaanya dari para pesaingnya. 


\subsection{Brand Equity}

Aaker dalam Akbar (2012) mendefinikan brand equity sebagai seperangkat asset dan lialibilitas merek yang berkaitan dengan suatu merek, nama, dan simbolnya yang menambah atau mengurangi nilai yang diberikan oleh sebuah barang atau jasa kepada perusahaan atau para konsumen atau pelanggan. Berikut adalah dimensi Brand Equity:

\section{a. Brand Awareness}

East dalam Akbar (2013) mengungkapkan bahwa brand awareness adalah kesadaran kepada konsumen atau calon konsumen untuk dapat mengenali atau mengingat kembali suatu merek dengan diferensiasinya terhadap merek lain yang sejenis.

\section{b. Perceive Quality}

David Aaker dalam Kartajaya (2010:73) mendefinisikan perceive quality sebagai persepsi pelanggan terhadap kualitas atau keunggulan suatu produk atau jasa sehubungan dengan tujuan yang diinginkannya, dibandingkan dengan alternative-alternatif lain.

\section{c. Brand Association}

David Aaker dalam Kartajaya (2010:66) mendefinikan brand association sebagai segala sesuatu yang terhubung di memori konsumen terhadap suatu merek.

\section{d. Brand Loyality}

Freddy Rangkuti (2008:60) mengungkapkan bahwa brand loyalityy merupakan satu ukuran dari kesetiaan konsumen terhadap suatu merek.

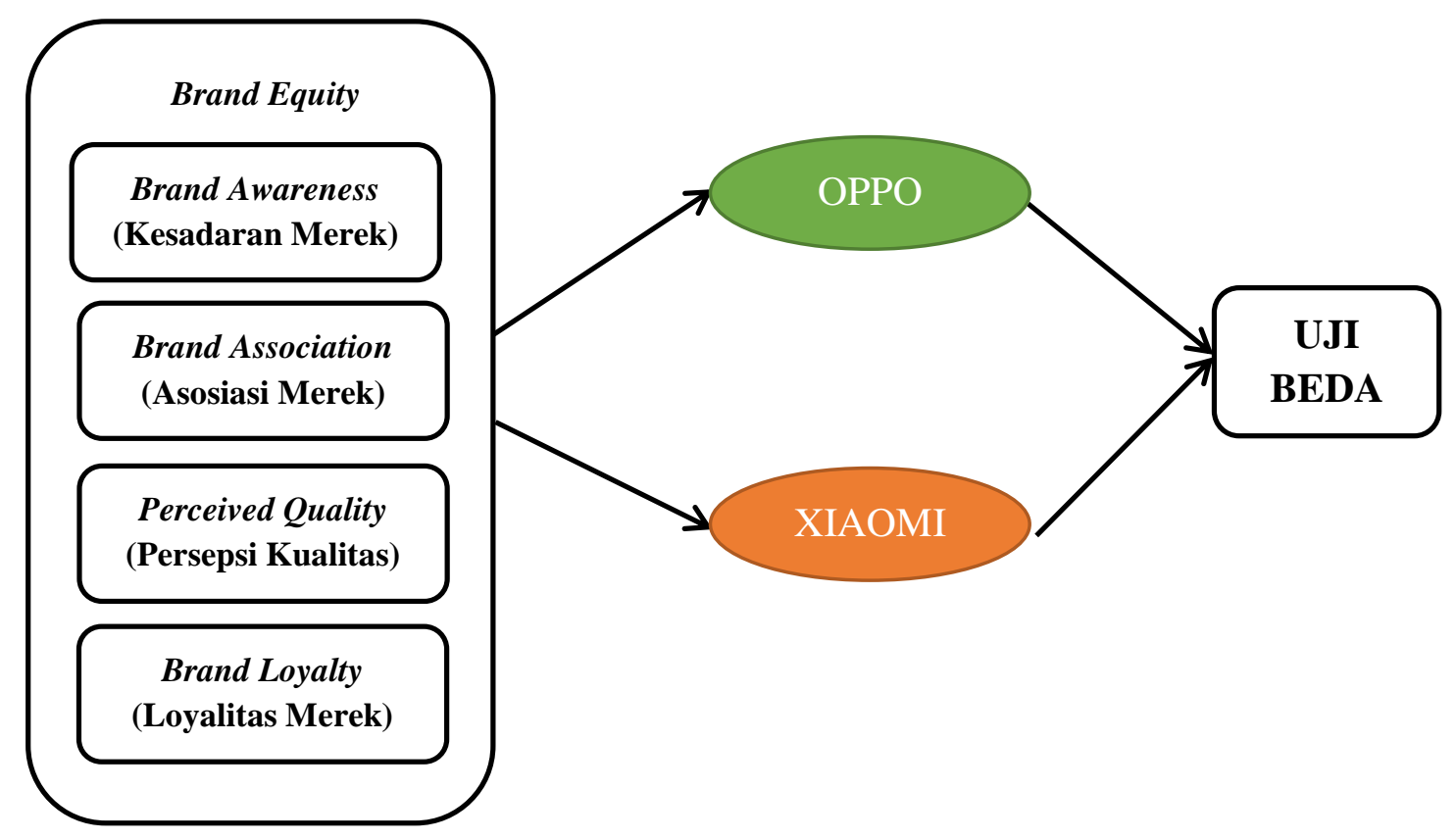

\section{HIPOTESIS}

Gambar 2 Kerangka Berpikir

Berdasarkan kerangka berpikir diatas maka dapat ditarik kesimpulan bahwa hipotesis penelitian ini adalah sebagai berikut:

H1: Terdapat perbedaan antara brand awareness Smartphone merek Oppo dan Xiaomi.

H2: Terdapat perbedaan antara brand association Smartphone merek Oppo dan Xiaomi.

H3: Terdapat perbedaan antara perceived quality Smartphone merek Oppo dan Xiaomi.

H4: Terdapat perbedaan antara brand loyalty Smartphone merek Oppo dan Xiaomi. 


\section{METODE}

Jenis penelitian ini menggunakan pendekatan kuatitatif dengan metode survey yang bersifat deskriptif komparatif. Skala pengukuran pada penelitian ini menggunakan skala likert. Populasi pada penelitian ini ditujukkan pada pengguna smartphone Oppo dan Xiaomi di Plaza Marina Surabaya. Sampel pada penelitian ini berjumlah 100 responden dengan masing-masing 50 responden Oppo dan 50 responden Xiaomi

\section{HASIL DAN PEMBAHASAN}

\subsection{HASIL}

\section{a. Uji Validitas}

Uji validitas merupakan uji instrument yang digunakan dalam penelitian apakah kuesioner sudah valid atau belum. Nilai validitas diindikasikan dengan nilai r-hitung hasil output SPSS pada masing-masing pernyataan. Item permnyataan dianggap valid apabila nilai r-hitung lebih besar atau sama dengan nilai r-tabel. Pada r-tabel menggunakan signifikansi 5\%. Nilai r-tabel untuk n:100 atau $\mathrm{df}(\mathrm{n}-2)$ adalah 0,1966 atau dibulatkan menjadi 0,197 .

Tabel 1 Uji Validitas

\begin{tabular}{|c|c|c|c|c|c|}
\hline Variabel & Item & ritabel & $\begin{array}{l}\text { Fhitung } \\
\text { Oppo }\end{array}$ & $\begin{array}{l}\text { Fhitung } \\
\text { Xisomi }\end{array}$ & Keterangan \\
\hline \multirow[t]{4}{*}{ Brand Awareness } & 1 & \multirow[t]{4}{*}{0,197} & 0,808 & 0.725 & Valid \\
\hline & 2 & & 0,839 & 0,680 & Valid \\
\hline & 3 & & 0,771 & 0,869 & Valid \\
\hline & 4 & & 0,880 & 0,731 & Valid \\
\hline \multirow[t]{4}{*}{ Perceived Quality } & 1 & \multirow[t]{4}{*}{0,197} & 0,8192 & 0,701 & Valid \\
\hline & 2 & & 0,1120 & 0,715 & Valid \\
\hline & 3 & & 0,1330 & 0,761 & Valid \\
\hline & 4 & & 0,771 & 0,759 & Valid \\
\hline \multirow[t]{3}{*}{ Brand Aasoeiation } & 1 & \multirow[t]{3}{*}{0,107} & 0,936 & 0.771 & Valid \\
\hline & 2 & & 0,842 & 0,850 & Valid \\
\hline & 3 & & 0,828 & 0,713 & Valid \\
\hline \multirow[t]{5}{*}{ Brand Loyalty } & 1 & \multirow[t]{5}{*}{0,197} & 0,851 & 0,745 & Valid \\
\hline & 2 & & 0,816 & 0,744 & Valid \\
\hline & 3 & & 0,002 & 0,853 & Valid \\
\hline & 4 & & 0,861 & 0,854 & Valid \\
\hline & 5 & & 0,882 & 0,850 & Valid \\
\hline
\end{tabular}

Tabel 1 menunjukkan bahwa nilai r-hitung untuk variabel Brand Awareness, Perveice Quality, Brand Association, Brand Loyality adalah lebih besar dari r-tabel $(0,197)$. Dapat disimpulkan bahwa seluruh item pernyataan dalam penelitian adalah valid.

Tabel 2 Uji Realibilitas

\begin{tabular}{|c|c|c|c|c|}
\hline Variabel & $\begin{array}{l}\text { Nilai } \\
\text { Croubach } \\
\text { Alpha }\end{array}$ & $\begin{array}{l}\text { Crosbach } \\
\text { Alpha Oppo }\end{array}$ & $\begin{array}{l}\text { Crophach } \\
\text { Algha Xiscuni }\end{array}$ & Keterangal \\
\hline $\begin{array}{l}\text { Brand } \\
\text { Awareness }\end{array}$ & 0,60 & 0,861 & 0.643 & Reliabel \\
\hline $\begin{array}{l}\text { Percepied } \\
\text { Quality }\end{array}$ & & 0.834 & 0,712 & Reliabel \\
\hline $\begin{array}{l}\text { Brand } \\
\text { Ausociatica }\end{array}$ & & 0.833 & 0.670 & Reliabel \\
\hline Brand Loyalty & & 0,910 & 0.865 & Reliabe! \\
\hline
\end{tabular}

Berdasarkan tabel 2 Diketahui bahwa variabel dalam kuesioner yaitu brand awareness, brand association, perceived quality, dan brand loyalty produk Smartphone Oppo Dan Xiaomi memiliki nilai alpha cronbach lebih besar dari nilai kritis 0.6, sehingga 
kuesioner yang mengukur brand awareness, brand association, perceived quality, dan brand loyalty produk Smartphone Oppo dan Xiaomi dinyatakan reliabel.

Tabel 3 Hasil Uji Homogenitas Varian Brand Awareness (Sig)

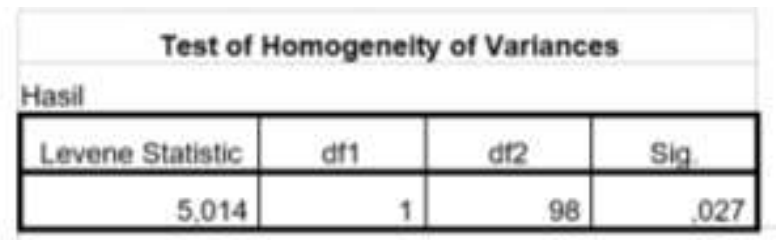

Hasil Analisa pada tabel 3 menunjukkan bahwa sig $<0.05(0.027<0.05)$, maka dapat diketahui bahwa Brand Awareness OPPO dan Xiaomi memiliki varian data yang tidak sama (unequal varian).

Tabel 4 Hasil Uji Homogenitas Varian Perceive Quality (Sig)

\begin{tabular}{|c|c|c|c|}
\hline \multicolumn{4}{|c|}{ Test of Homogeneity of Variances } \\
\hline Hasil & & & \\
\hline Levene Statistic & df1 & $\mathrm{d} 12$ & $\operatorname{sig}$. \\
\hline 6.897 & 1 & 98 & .010 \\
\hline
\end{tabular}

Hasil Analisa pada tabel 4 menunjukkan bahwa sig $<0.05(0.010<0.05)$, maka dapat diketahui bahwa Perceive Quality OPPO dan Xiaomi memiliki varian data yang tidak sama (unequal varian).

Tabel 5 Hasil Uji Homogenitas Varian Brand Assciation (Sig)

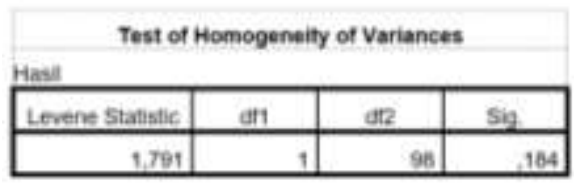

Hasil Analisa pada tabel 5 menunjukkan bahwa sig > 0.05 (0.184 > 0.05), maka dapat diketahui bahwa brand association OPPO dan Xiaomi memiliki varian data yang sama (equal varian).

Tabel 6 Hasil Uji Homogenitas Varian Brand Loyality (Sig)

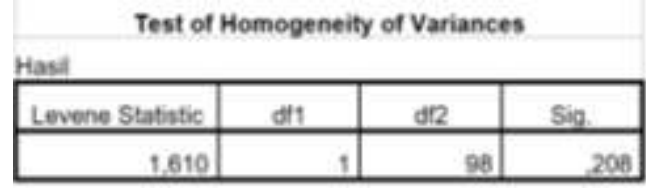

Hasil Analisa pada tabel 6 menunjukkan bahwa sig > $0.05(0.208>0.05)$, maka dapat diketahui bahwa brand loyality OPPO dan Xiaomi memiliki varian data yang sama (equal varian). 


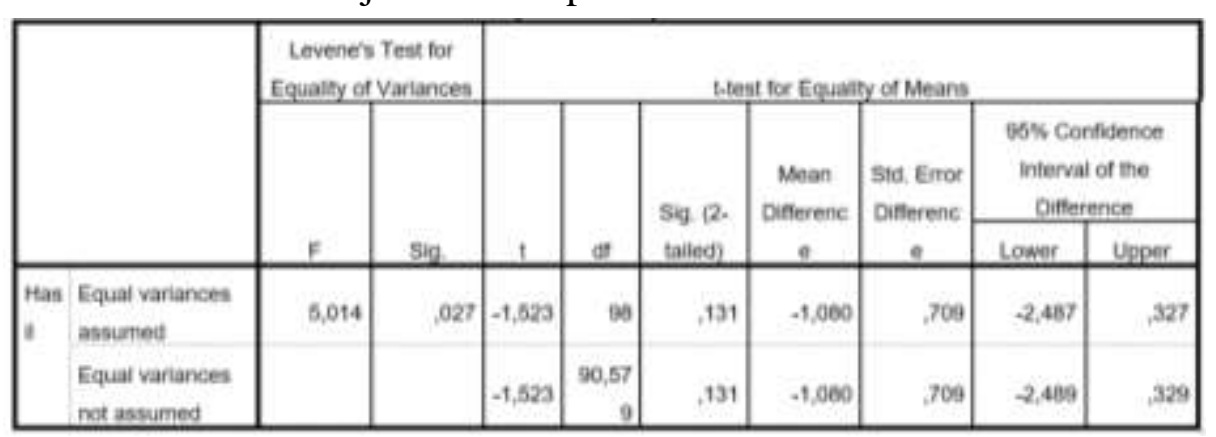

Berdasarkan Tabel 7 maka dapat diketahui hasil hitung uji $\mathrm{T}$ pada sampel independen memiliki nilai signifikansi 2-tailed sebesar 0.131. maka $0.131>0.05$, sehingga dapat diketahui bahwa terdapat perbedaan yang tidak signifikan antara brand awareness smartphone merek OPPO dan merek Xiaomi.

Tabel 8 Uji Beda Independent T-Test Perceive Quality

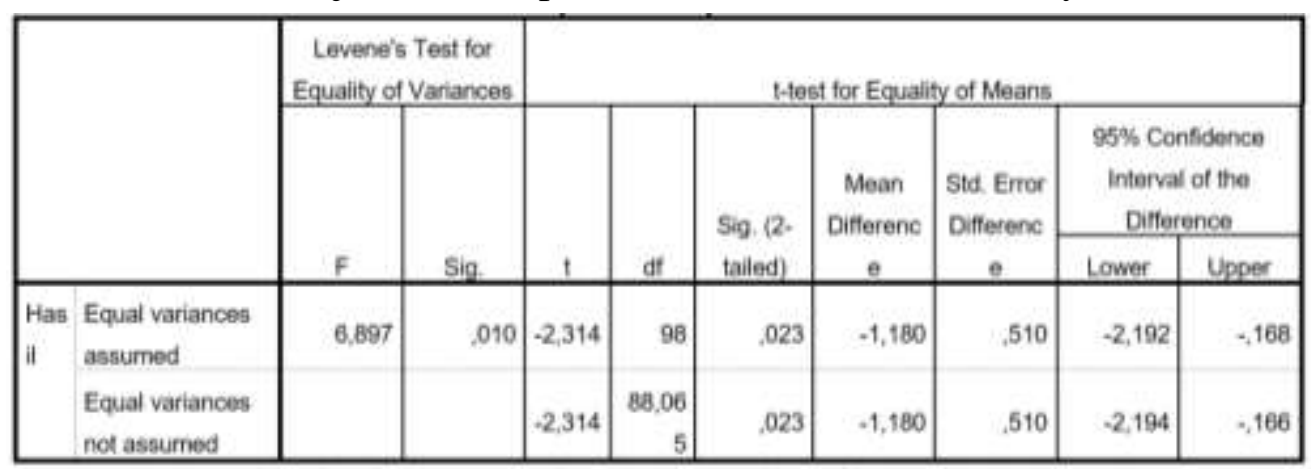

Berdasarkan Tabel 8 maka dapat diketahui hasil hitung uji T pada sampel independen memiliki nilai signifikansi 2 -tailed sebesar 0.023 . maka $0.023<0.05$, sehingga dapat diketahui bahwa terdapat perbedaan yang signifikan antara perceive quality smartphone merek OPPO dan merek Xiaomi.

Tabel 9 Uji Beda Independent T-Test Brand Association

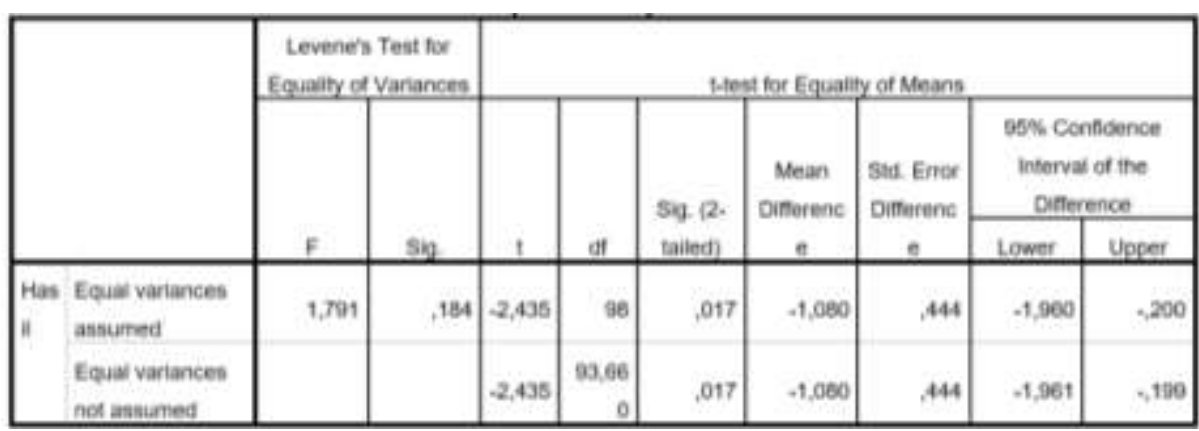

Berdasarkan Tabel 9 maka dapat diketahui hasil hitung uji T pada sampel independen memiliki nilai signifikansi 2-tailed sebesar -0.017. maka $0.017<0.05$, sehingga dapat diketahui bahwa terdapat perbedaan yang signifikan antara brand association smartphone merek OPPO dan merek Xiaomi. 
Tabel 10 Uji Beda Independent T-Test Brand Loyality

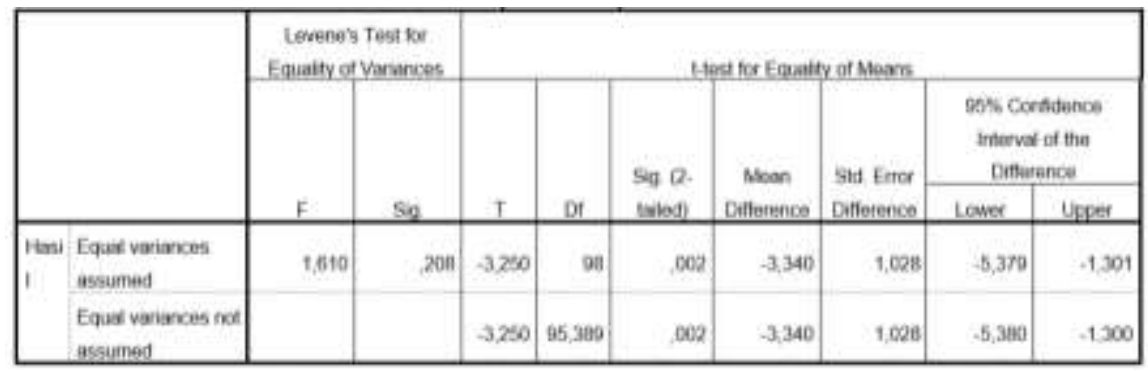

Berdasarkan Tabel 10 maka dapat diketahui hasil hitung uji T pada sampel independen memiliki nilai signifikansi 2-tailed sebesar 0.002. maka $0.002<0.05$, sehingga dapat diketahui bahwa terdapat perbedaan yang signifikan antara brand loyalty smartphone merek OPPO dan merek Xiaomi.

\subsection{PEMBAHASAN}

\section{A. Analisis Komparasi Berdasarkan Indikator Brand Awareness}

Berdasarkan Indikator Brand Awareness, terdapat perbedaan yang tidak signifikan antara smartphone merek OPPO dan Xiaomi. Melalui uji t sampel independen diperoleh tingkat signifikansi sebesar 0.131 yang lebih besar dari 0.05, sehingga H0 diterima dan Ha ditolak.

\section{B. Analisis Komparasi Berdasarkan Indikator Perceived Quality}

Berdasarkan Indikator Perceive Quality, terdapat perbedaan yang signifikan antara smartphone merek OPPO dan Xiaomi. Melalui uji t sampel independen diperoleh tingkat signifikansi sebesar 0.023 yang kurang dari 0.05 , sehingga $\mathrm{H} 0$ ditolak dan Ha diterima.

\section{Analisis Komparasi Berdasarkan Indikator Brand Association}

Berdasarkan Indikator Brand Association, terdapat perbedaan yang signifikan antara smartphone merek OPPO dan Xiaomi. Melalui uji t sampel independen diperoleh tingkat signifikansi sebesar 0.017 yang kurang dari 0.05, sehingga H0 ditolak dan Ha diterima.

\section{Analisis Komparasi Berdasarkan Indikator Brand Loyality}

Berdasarkan Indikator Brand Loyality, terdapat perbedaan yang signifikan antara smartphone merek OPPO dan Xiaomi. Melalui uji t sampel independen diperoleh tingkat signifikansi sebesar 0.002 yang kurang dari 0.05 , sehingga $\mathrm{H} 0$ ditolak dan Ha diterima.

\section{KESIMPULAN DAN SARAN \\ 6.1 KESIMPULAN}

Hasil analisa data dan pembahasan menunjukkan bahwa Brand Equity yang meliputi Brand Awareness, Perceived Quality, Brand Association, dan Brand Loyality dilakukan uji statistik untuk mengetahui perbedaannya antara smartphone merek OPPO dan Xiaomi. Berdasarkan indikator Brand Awareness diperoleh nilai Sig(2-tailed) yang lebih besar dari 0.05 $(0.131>0.05)$ sehingga dapat disimpulkan bahwa terdapat perbedaan yang tidak signifkan antara Brand Equity pada smartphone merek OPPO dan Xiaomi. Berdasarkan Perceived Quality diperoleh nilai Sig(2-tailed) yang lebih kecil dari 0.05 atau sebesar $0.023(0.023<0.05)$ sehingga dapat disimpulkan bahwa terdapat perbedaan yang signifikan antara Perceived Quality smartphone merek OPPO dan Xiaomi. Hasil Uji beda indikator Brand Association menunjukkan nilai $\operatorname{Sig}$ (2-tailed) sebesar 0.017 yang kurang dari 0.05, yang memiliki arti terdapat perbedaan yang signifikan antara Brand Association pada smartphone merek OPPO dan Xiaomi. Untuk Indikator Brand Loyality diperolehg nilai Sig(2-tailed) sebesar 0.002 yang kurang dari 0.05 . sehingga dapat disimpulkan bahwa terdapat perbedaan yang signifikan antara Brand Loyality pada smartphone merek OPPO dan Xiaomi. 


\subsection{SARAN}

1. Perusahaan OPPO dan Xiaomi sebaiknya lebih meningkatkan Brand Equity pada indikator Brand Awareness, Perceived Quality, Brand Association, dan Brand Loyality sebesar satu satuan, sehingga konsumen yang sebelumnya memberikan tanggapan "Setuju" menjadi "Sangat Setuju" yang artinya Brand Equity dari Smartphone merek OPPO dan Xiomi telah melekat di pemikiran para konsumen dan mampu menguasai pasar.

2. Peningkatan Brand Equity dapat dilakukan dengan peningkatan kualitas produk dan citra merek yang dapat menunjang Brand Awareness, Perceived Quality, Brand Association, dan Brand Loyality.

3. Bagi penelitian selanjutnya sebaiknya mengembangkan indikator-indikator dari Brand Equity, atau dapat melakukan penelitian komparasi Brand Equity pada objek lainnya.

\section{DAFTAR PUSTAKA}

Abdullah, Thamrin., and Francis Tantri. 2012. Manajemen Pemasaran. PT Raja Grafindo Persada: Jakarta.

Adam Akbar, 2012, Jurnal Analisis Pengaruh Citra Merek, Harga, dan Kualitas Produk Terhadap Keputusan Pembelian Notebook Toshiba, Jurnal Managemen Pemasran,3, 16-19

Ali, Hasan. 2013. Marketing dan Kasus-Kasus Pilihan. Yogyakarta. CAPS (Center For Academic Publishing Service)

Alma, Buchari. 2013. Manajemen Pemasaran dan Pemasaran Jasa. Bandung: Alfabeta.

K.L. Keller. 2009. Manajemen Pemasaran. Edisi kedua belas. jilid 1. PT Index. kelompok Gramedia. Jakarta

Daryanto. 2011. Manajemen Pemasaran: Sari Kuliah. Bandung: Satu Nusa

Ferrinadewi, Erna, 2008, Merek \& Psikologi Konsumen Implikasi pada Strategi Pemasaran, edisi Pertama, Graha Ilmu, Yogyakarta

Freddy Rangkuti, 2008, The Power Of Brands, Jakarta: Penerbit Gramedia

Ghozali, Imam. 2016. Aplikasi Analisis Multivariete Dengan Program IBM SPSS 23 (Edisi 8). Cetakan ke VIII. Semarang: Badan Penerbit Universitas Diponegoro

Kertajaya, Hermawan. 2010. Brand Operation. Jakarta: Esensi Erlangga Group

Kotler Philip, Amstrong Gary. 2013. Prinsip-prinsip Pemasaran, Edisi ke-12. Penerbit Erlangga.

Kotler, P. \& Keller, K.L. (2012), Manajemen Pemasaran Jilid I Edisi ke 12. Jakarta: Erlangga.

Kotler, Philip and Kevin Lane Keller, 2016. Marketing Managemen, 15th Edition, Pearson Education,Inc.

Kotler, Philip dan Amstrong, Gary, (2014), Principles of Marketin, 12th Edition, Jilid 1 Terjemahan Bob Sabran Jakarta: Erlangga. 
Kurtz, David L. Bone, 2012. Principle of Contemporary Marketing, 14th Edition, Cenbage Learning, USA.

Sudarmanto,R. Gunawan.2013.Statistik Terapan Berbasis Komputer Dengan Program IBM SPSS Statistics 19.Jakarta:PT Mitra Wacana Media

Sugiyono, (2015). Statistik Nonparametis Untuk Penelitian. Bandung: Alfabeta.

Sugiyono. (2014). Metode Penelitian Kuantitatif Kualitatif dan R\&D. Bandung: Alfabeta.

Tjiptono, Fandy, 2008, Strategi Pemasaran, Edisi 3, ANDI: Yogyakarta. 